\title{
Enhanced phenol degradation by immobilized Acinetobacter sp. strain AQ5NOL 1
}

\begin{abstract}
A locally isolated Acinetobacter sp. Strain AQ5NOL 1 was encapsulated in gellan gum and its ability to degrade phenol was compared with the free cells. Optimal phenol degradation was achieved at gellan gum concentration of $0.75 \%(\mathrm{w} / \mathrm{v})$, bead size of $3 \mathrm{~mm}$ diameter (estimated surface area of $28.26 \mathrm{~mm} 2$ ) and bead number of 300 per $100 \mathrm{ml}$ medium. At phenol concentration of $100 \mathrm{mg}$ li 1 , both free and immobilized bacteria exhibited similar rates of phenol degradation but at higher phenol concentrations, the immobilized bacteria exhibited a higher rate of degradation of phenol. The immobilized cells completely degrade phenol within 108, 216 and $240 \mathrm{~h}$ at 1,100, 1,500 and 1,900 mg lī 1 phenol, respectively, whereas free cells took $240 \mathrm{~h}$ to completely degrade phenol at 1,100 $\mathrm{mg}$ li 1 . However, the free cells were unable to completely degrade phenol at higher concentrations. Overall, the rates of phenol degradation by both immobilized and free bacteria decreased gradually as the phenol concentration was increased. The immobilized cells showed no loss in phenol degrading activity after being used repeatedly for 45 cycles of $18 \mathrm{~h}$ cycle. However, phenol degrading activity of the immobilized bacteria experienced 10 and $38 \%$ losses after the 46 and 47 th cycles, respectively. The study has shown an increased efficiency of phenol degradation when the cells are encapsulated in gellan gum.
\end{abstract}

Keyword: Gellan gum; Immobilized cell; Phenol degradation; Acinetobacter sp. 